\title{
The Behavior of Polymeric Blends (PP + PA6) in Tensile Tests
}

\author{
ANDREEA ELENA MUSTEATA ${ }^{1}$, GEORGE PELIN ${ }^{2}$, MIHAIL BOTAN², \\ ADRIAN POPESCU ${ }^{3}$, LORENA DELEANU ${ }^{1 *}$ \\ ${ }^{1}$ Faculty of Engineering „Dunarea de Jos”, Department of Mechanical Engineering, 111 Domneasca Str., 800201, Galati, \\ Romania \\ ${ }^{2}$ National Institute for Aerospace Research „Elie Carafoli” INCAS, 220 Iuliu Maniu Blvd., 061126, Bucharest, Romania \\ ${ }^{3}$ Technical University of Cluj-Napoca, Faculty of Machine Building, Department of Manufacturing Engineering, 28 \\ Memorandumului Str., 400114, Cluj-Napoca, Romania
}

\begin{abstract}
This paper presents the influence of component concentration for a class of polymeric blends with different concentration of PP (polypropylene) and PA6 (polyamide 6) and a constant concentration of additives: $\mathrm{CaCO}_{3}, \mathrm{LDPE}$ (low density polyethylene) and a compatibilizer POLYBOND® 3200. Mechanical properties has been investigated for four different test speeds, from $10 \mathrm{~mm} / \mathrm{min}$ to $1000 \mathrm{~mm} / \mathrm{min}$. Young's modulus performs in a band between $1500 \ldots 1900 \mathrm{MPa}$, except for the value for PA6 at the lowest testing speed ( $v=10 \mathrm{~mm} / \mathrm{min})$, that is $1444 \mathrm{MPa}$. At high concentration of PA6, there were noticed voids in the longitudinal direction of the samples, forming large parallel 'empty channels', as the two polymers are immiscible. Except for values at low testing speed, the average values for tensile stress at break perform in a band of less than $8 \mathrm{MPa}$. The elongation at break is less than 10\% for all materials, except for PA6 at the lowest testing speed, when a higher value was obtained. The lowest values were obtained for the blend with 20\% PA6. For blends with $60 \%$ and $80 \%$ PA6, the difference between values, at the same testing speed, is the smallest. Energy at break has a slightly increase with the concentration of PA6. From the mechanical point of view, among the formulated blends, material D (with 80\% PA6) is the most promising as has the highest values for stress and energy at break $(11.8 \mathrm{~J}$ at $v=10 \mathrm{~mm} / \mathrm{min}$ and $9.6 \mathrm{~J}$ at $v=1000 \mathrm{~mm} / \mathrm{min})$, but values are still less than those for PA6.
\end{abstract}

Keywords: polyamide, polypropylene, blend, tensile characterization, energy at break, elongation

\section{Introduction}

As polymeric blends have complex behavior, tests and comparing data are necessary to avoid failure and to select the appropriate combination of polymers for a particular application. Relevant works [1-5] pointed out that morphology of polymeric blends influence their characteristics. Polymer blends could tailor their mechanical and thermal properties, keeping some advantages of expensive polymers and reducing non-desired features of low-cost ones $[6,7]$.

Researchers are still interested in polypropylene (PP) [8] and polyamide (PA6) due to their characteristics (table 1). Polyamide/polypropylene (PA/PP) blends have applications because both components are relatively cheap, with advantageous mechanical properties and are processable by melt blending and molding. The compatibilization of binary polymer blends may be made by adding graft copolymer, segments of which have physical or chemical affinity with the two immiscible polymers [9, 10], [11]. Wang et al. [12] used organoclay (a montmorillonite organically modified with a quaternary ammonium, till 3\%wt) and maleic anhydride grafted polypropylene (till $10 \% \mathrm{wt}$ ) as compatibilizers for blends PP+PA66, keeping constant the concentration of PA66 (30\%wt) to improve the morphology, by reducing the sea-island morphology obtained without organoclay.

Ide and Hasegawa [13] made them compatible by using grafting with a maleic anhydride modified polypropylene in 1974, but polyamide + polypropylene blends were introduced on the market in the last decade of the XXth century.

\footnotetext{
*email: lorena.deleanu@ugal.ro
} 
Table 1 comparatively presents properties of each polymer, polyamide and polypropylene, respectively.

Table 1. Characteristics of the two polymers [14]

\begin{tabular}{|l|l|l|}
\hline Property & PA6, PA66 & PP \\
\hline Melting/softening temperature & high & moderate \\
\hline Glass transition temperature & low & low \\
\hline Melt processability & excellent & excellent \\
\hline Moisture absorption & high & none \\
\hline Moisture sensitivity & high & none \\
\hline Drop weight impact strength & high & moderate \\
\hline Notched Izod impact & low & low \\
\hline Tensile strength & high (dry) & moderate \\
\cline { 2 - 2 } & moderate (wet) & \\
\hline $\begin{array}{l}\text { Solvent resistance } \\
\text { Hydrocarbons, oils }\end{array}$ & excellent & moderate \\
$\begin{array}{l}\text { Paint solvents } \\
\text { Alcohols, glycols }\end{array}$ & excellent \\
$\begin{array}{l}\text { Hydrolysis resistance } \\
\text { (in acid or basic water solutions) }\end{array}$ & poor & excellent \\
\hline
\end{tabular}

Blends PP + PA are usually in 50/50 to 60/40 ratio and exhibit significantly slower rate of moisture/water absorption as compared to polyamides due to the presence of the moisture resistant polypropylene phase, they have low costs, improved dimensional stability and the behavior in moisture environments is better.

Investigations on of PA + PP blends have also been reported by Sangroniz et al. in 2016 [15]; Alexandrescu et al. in 2017 [16] and Shi et al. [7] also in 2017.

The characterization of deformation damage mechanisms in polymer blends based on polypropylene and polyamides was studied by Beuguel [17] revealing that higher viscosity of polypropylene matrix had influenced the interfacial coverage of polyamide nodules, by slowing down the migration of fillers from polypropylene matrix to polyamide nodules. Kodal [18] pointed out by scanning electron microscopy that the dispersed phase particles size was reduced in the presence of polyhedral oligomeric silsesquioxane nanoparticles. Yield and impact strength increased as the concentration of the nanoparticles increased from 1 to $5 \mathrm{wt} \%$ regardless their type. Motamedi and Bagheri [19] studied polypropylene/polyamide 6/layered silicate blends, prepared through three different processing procedures. Tensile and impact strength measurements were affected by the processing procedure.

Chen et al. [20] led to the conclusion that the influence of cavitation on the overall response of the material depends to many factors including processing parameters, presence of compatibilizing agents, cooling, applied strain rate, particle-size distribution and relaxation time of the matrix.

This paper presents results on the tensile behavior of four blends PP + PA6, with the same content of additives for compatibilization, in order characterize these new materials for future applications.

\section{Polymeric blends and manufacturing technology}

Immiscible polymers blends exhibit sea-island morphologies with large droplet sizes and a lack of adhesion between components, as a result of the high interfacial tension between the two immiscible phases. Thus, these blends generally exhibit poor mechanical properties, since mechanical performance is a function of blend morphology and interfacial interactions. To overcome these issues, several compatibilization strategies that include adding block copolymers, compatibilizing agents and nanoparticles have been developed in the last few decades [14, 21, 22- 24].

Bone samples for tensile test were prepared by melt extrusion in a molding machine at Monofil Savinesti Romania. The components in each material to be tested are given in Table 2. A simplified diagram of processing the samples is given in figure 1. 


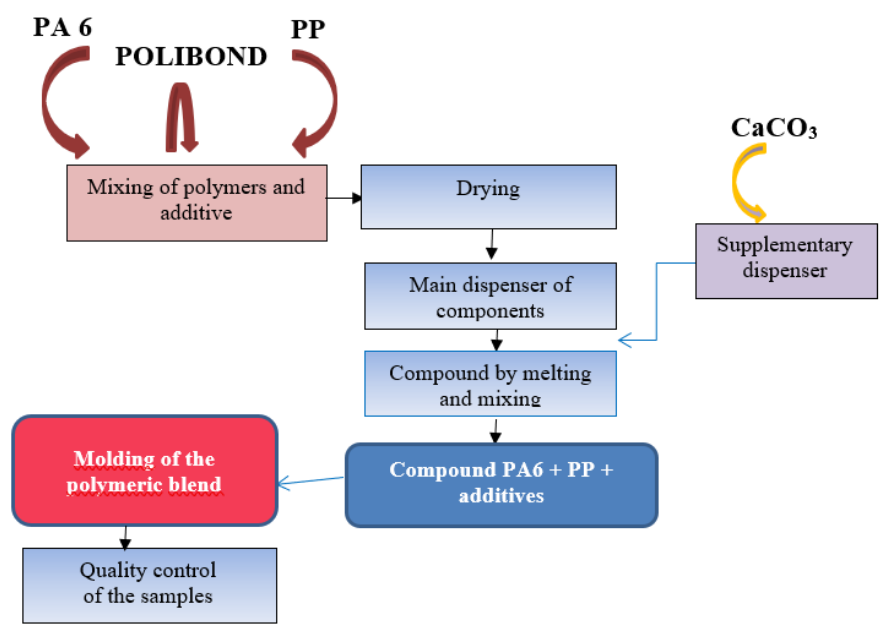

Figure 1. Technology of sample manufacturing

Linear low density polyethylene (LLDPE) has significant short branches and differs structurally from conventional low-density polyethylene because of the absence of long chain branching. The copolymerization process produces an LLDPE polymer that has a narrower molecular weight distribution than conventional LDPE and in combination with the linear structure, significantly influences rheological properties.

Omyacarb 5 [25] was added for dispersing purpose and it contains 98\%wt $\mathrm{CaCO}_{3}$ (average size 6 $\mu \mathrm{m}$, specific gravity $2.70 \mathrm{~g} / \mathrm{cm}^{3}$, specific surface area $2.1 \mathrm{~m}^{2} / \mathrm{g}$ ) and it is a good extender for polymeric blends, elastomers.

Ippolito et al. [22] studied the influence of calcium carbonate as a mineral filler particle on thermal properties in compression-molded polyamide 12. The particle size distribution and the filler amount within the polyamide 12 matrix were varied and the thermal and flow properties of polyamide 12 matrix were influenced by adding these particles.

POLYBOND® 3200 [26] is a polymer modifier based on chemically modified PP and is a good compatibilizer for blends, including polypropylene/polyamide, to improve processibility and mechanical properties.

Table 2. Symbols of formulated materials

\begin{tabular}{|c|c|c|c|c|c|}
\hline $\begin{array}{l}\bar{\partial} \\
\text { है } \\
\text { के }\end{array}$ & PA6 & PP & LLDPE & 预 & 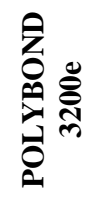 \\
\hline & \multicolumn{5}{|c|}{ Composition [wt\%] } \\
\hline $\mathbf{P P}$ & - & 100 & - & - & - \\
\hline $\mathbf{A}$ & 20 & 65 & 5 & 7 & 3 \\
\hline B & 40 & 45 & 5 & 7 & 3 \\
\hline C & 60 & 25 & 5 & 7 & 3 \\
\hline D & 80 & 5 & 5 & 7 & 3 \\
\hline PA6 & 100 & - & - & - & - \\
\hline
\end{tabular}

\section{Characteristics in tensile tests of the designed blends}

Samples made of neat polymers (PP and PA6, respectively) and four blends with different concentrations (table 2) were tested on the tensile test machine Instron 2736-004, at INCAS. The sample has a bone-shaped body, as type 1A, SR EN ISO 527-2 [27]. Only data from 5 tests were kept for calculating the average values of the mechanical characteristics, extreme curves, if singular, were avoided. 
In figures 2 and 3, typical stress-strain curves for PA6, PP and two blends are given for three different testing speeds. Tests were done for the following speeds: $10 \mathrm{~mm} / \mathrm{min}, 250 \mathrm{~mm} / \mathrm{min}, 500$ $\mathrm{mm} / \mathrm{min}$ and $1000 \mathrm{~mm} / \mathrm{min}$. The curves for $500 \mathrm{~mm} / \mathrm{min}$ are not presented here as they are similar in shape to those for $1000 \mathrm{~mm} / \mathrm{min}$.

Taking into account the stress-strain curves, both neat polymers have exhibit a dual behavior at the lowest testing speed $(\mathrm{v}=10 \mathrm{~mm} / \mathrm{min})$. For PA6, some samples were broken at $20 \ldots 40 \%$ strain, but others were broken after $85 . .90 \%$. At higher test speeds $(250 \mathrm{~mm} / \mathrm{min} . . .1000 \mathrm{~mm} / \mathrm{min})$ PA6 has the elongation at break lower $(12 \ldots .23 \%)$

PP has several samples broken at $10 \ldots 15 \%$, others at higher values (till 17...25\%) with an intermediate plateau of stress till break between $10 \ldots 20 \mathrm{MPa}$ (engineering stress).

At low concentration of PA6 (20...40\%wt, materials A and B), the curves are very close and the strain at break has values in a narrow range (1.5\% for the blend with $20 \%$ PA6 and less than $1 \%$ for the blend with 40\% PA6). For higher contents of PA6 (materials C and D), the curves are similar, but spread on a larger space. At the higher testing speeds ( $\mathrm{v}=500 \mathrm{~mm} / \mathrm{min}$ and $\mathrm{v}=1000 \mathrm{~mm} / \mathrm{min}$, figure 2), PP has the curves almost overlapping. PA6 exhibits a distribution more distinct for each sample, with plateaux of stress, at approximately $40 \mathrm{MPa}$ for the lowest test speed in the yield zone and at approximately $50 \mathrm{MPa}$ for the other test speed
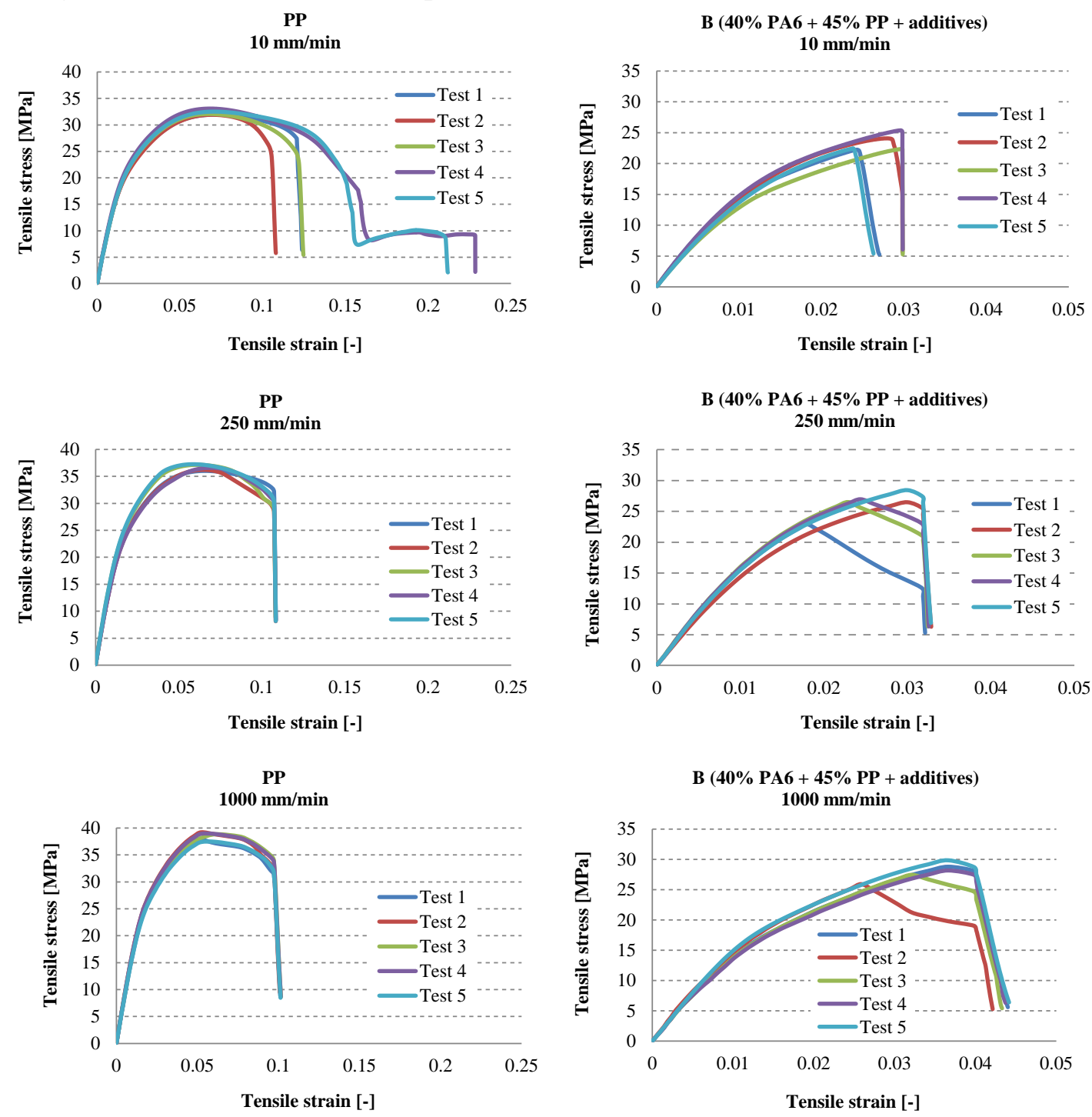

Figure 2. Test results for material PP (strain-stress curves)

Figure 3. Test results for material B (strain-stress curves 

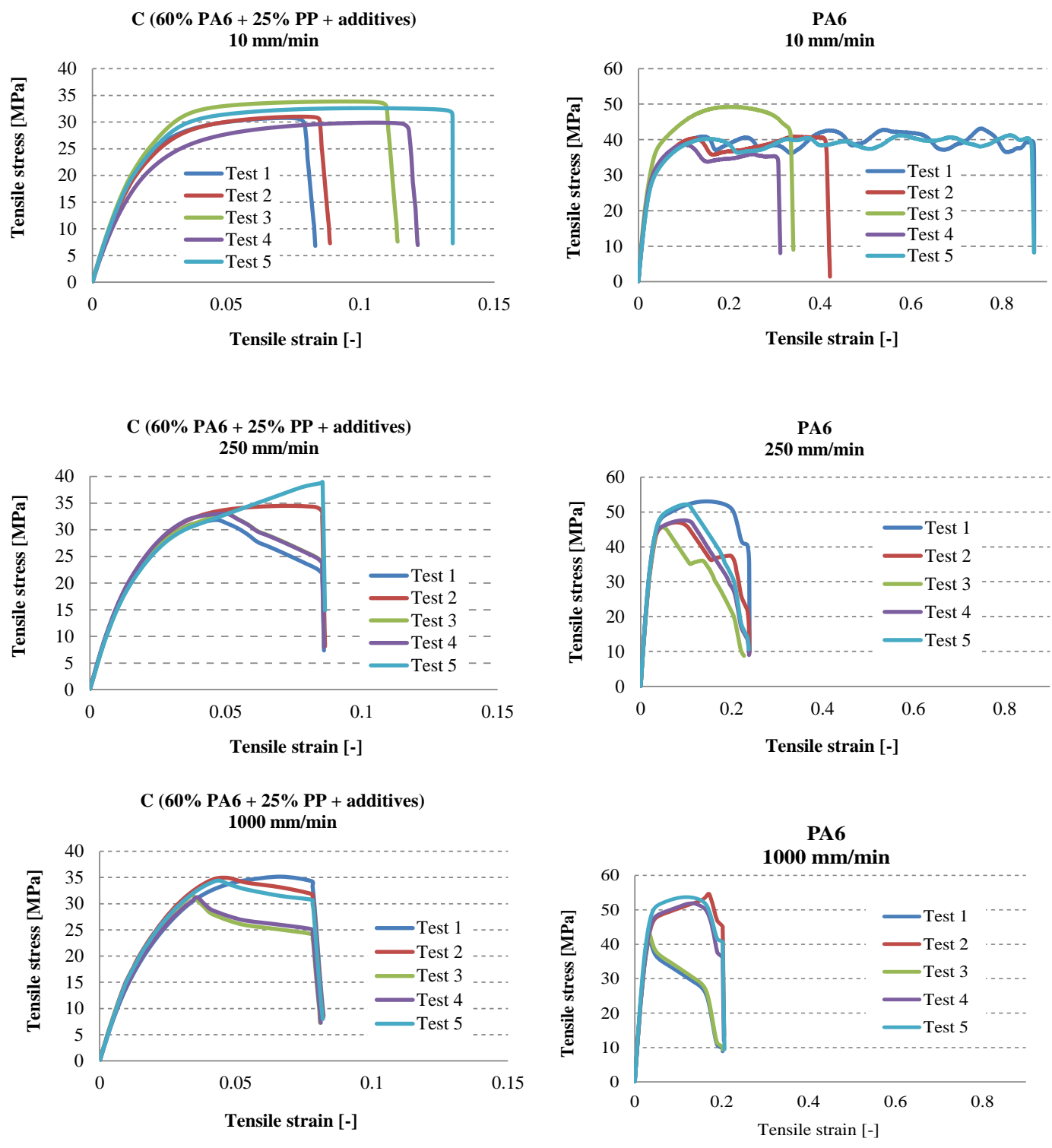

Figure 4. Test results for material C (strain - stress curves)

Figure 5. Test results for material PA6 (strain - stress curves)

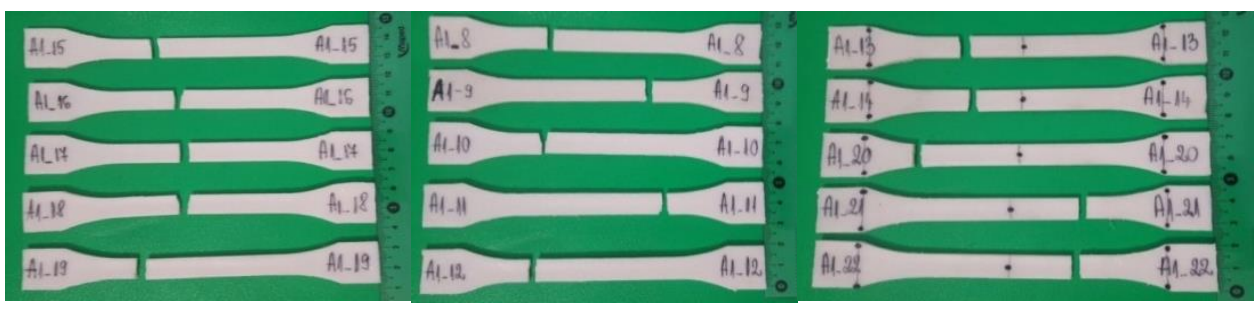

Figure 6. gives the images of the sample sets for material A

In this paper the following tensile characteristics are analysed: Young modulus (figure 7), stress at break (figure 8), elongation at break (figure 9) and energy at break (figure 10). The values in these graphs are obtained from averaging 5 valid tests.

Each characteristic is analysed based on the following relation, here written only for the Young modulus 


$$
\Delta E_{(1000)}=\frac{E_{(1000)}-E_{(10)}}{E_{(10)}} \cdot 100[\%]
$$

where $E_{(10)}$ is the value of Young modulus for traction speed $v=10 \mathrm{~mm} / \mathrm{min}$ and $E_{(1000)}$ is the value of Young modulus for traction speed $v=1000 \mathrm{~mm} / \mathrm{min}$. The results of this comparing data are given in table 2 .

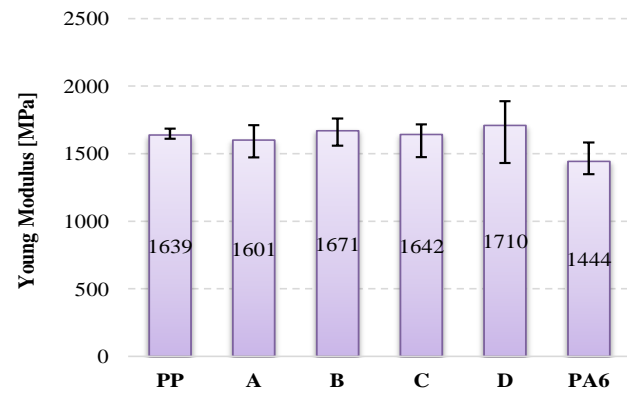

a) $10 \mathrm{~mm} / \mathrm{min}$

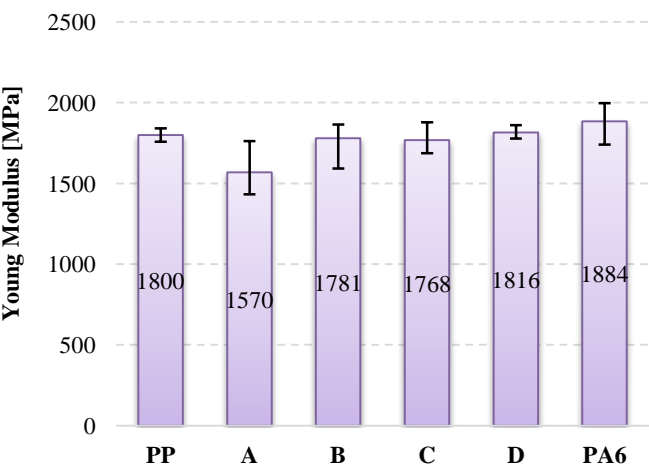

c) $500 \mathrm{~mm} / \mathrm{min}$

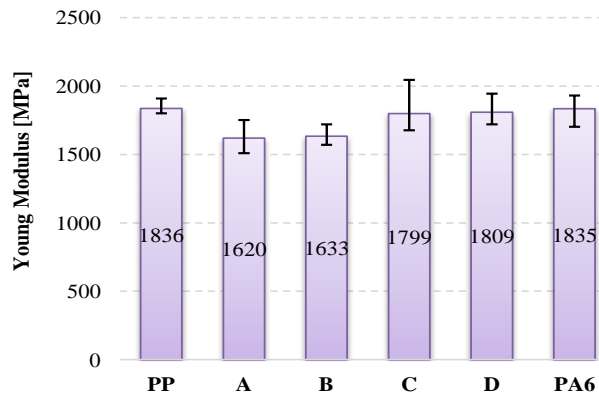

b) $250 \mathrm{~mm} / \mathrm{min}$

$$
2500
$$

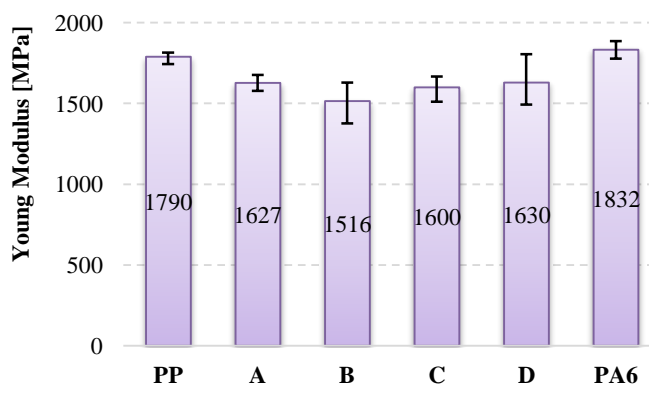

d) $1000 \mathrm{~mm} / \mathrm{min}$

Figure 7. Young modulus for all formulated blends at different testing speeds

Table 3. Results of comparing data for mechanical characteristics obtained at two test speeds, $10 \mathrm{~mm} / \mathrm{min}$ and $1000 \mathrm{~mm} / \mathrm{min}$

\begin{tabular}{|c|c|c|c|c|c|c|}
\hline & PP & A & B & C & D & PA6 \\
\hline$\frac{E_{(1000)}-E_{(10)}}{E_{(10)}} \cdot 100[\%]$ & 9.21 & 4.80 & -9.27 & -2.56 & -4.68 & 26.28 \\
\hline$\frac{\sigma_{r(1000)}-\sigma_{r(10)}}{\sigma_{r(10)}} \cdot 100[\%]$ & 102.8 & 12.39 & 21.21 & 10.70 & 13.49 & 58.96 \\
\hline$\frac{\varepsilon_{r(1000)}-\varepsilon_{r(10)}}{\varepsilon_{r(10)}} \cdot 100[\%]$ & -45.22 & -15.63 & 32.14 & -38.09 & -38.09 & -80.71 \\
\hline$\frac{E_{r(1000)}-E_{r(10)}}{E_{r(10)}} \cdot 100[\%]$ & -26.45 & -13.64 & 44.44 & -38.79 & -18.64 & -77.83 \\
\hline
\end{tabular}

Young modulus increased for PA6 with the test speed with $26.28 \%$, tested at $1000 \mathrm{~mm} / \mathrm{min}$ as compared to the value obtained for the testing speed of $10 \mathrm{~mm} / \mathrm{min}$. For PP, the same increase is only 9.21\%. For materials $\mathrm{B}, \mathrm{C}$ and $\mathrm{D}$, this ratio is negative, meaning that Young modulus is lower for the highest test speed. This could be explained by the fact that the actual cross section of the samples is diminished by the presence of voids. 
From table 2, one may notice that the increasing test speed does not increase the Young modulus and this could be explained by the void generation and sample response to tensile test. Young modulus does not spectacularly depends on blend concentration in PP and PA6, but, unexpectedly, this characteristic is less sensitive for $\mathrm{v}=10 \mathrm{~mm} / \mathrm{min}$ and $\mathrm{v}=1000 \mathrm{~mm} / \mathrm{min}$. For the intermediate test speeds $(\mathrm{v}=250 \mathrm{~mm} / \mathrm{min}$ and $\mathrm{v}=500 \mathrm{~mm} / \mathrm{min})$ there is a slight tendency of increasing it with the PA6 content. Thus, the concentration of components has no evident influence on this mechanical characteristic.

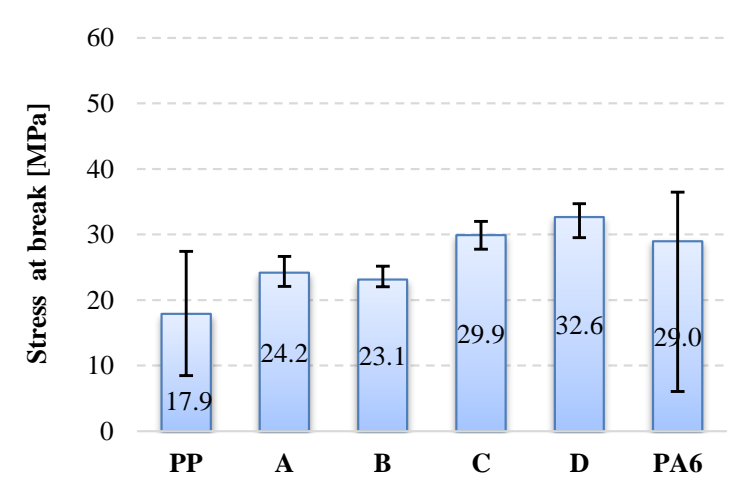

$10 \mathrm{~mm} / \mathrm{min}$

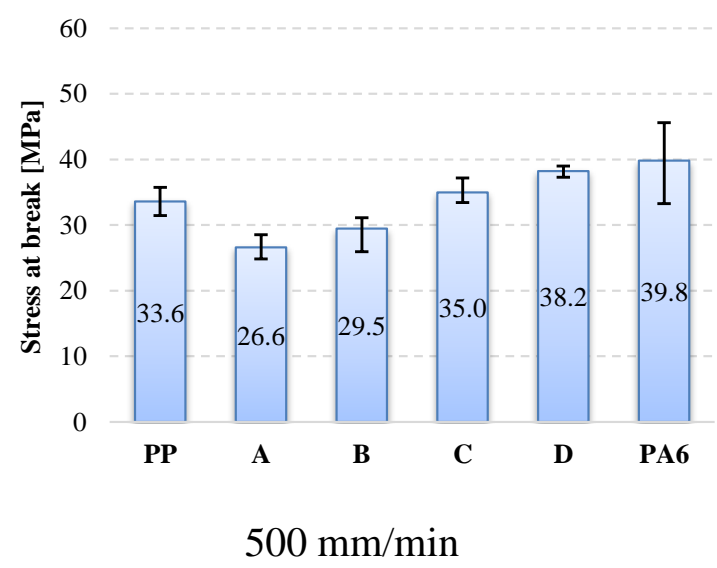

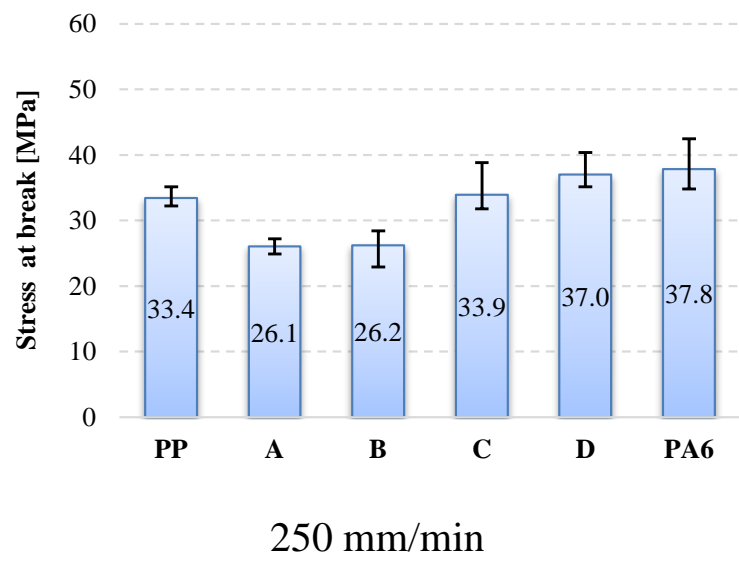

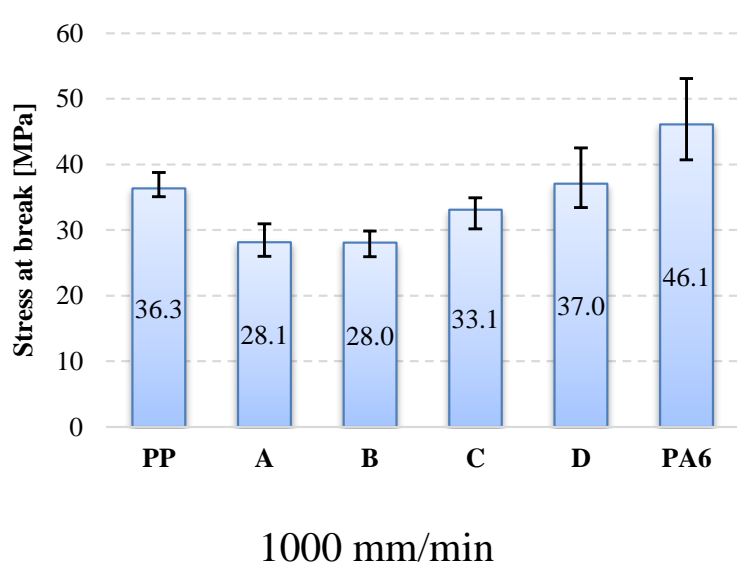

Figure 8. Stress at break for all formulated blends at different testing speed

Mindru et al. [28] did tensile tests on PA 6.6 and obtained similar shape of the plots for $5 \mathrm{~mm} / \mathrm{min}$ to those obtained with higher test speeds for PA6, but with lower value for PA6.

For the neat polymers, the highest test speed makes the stress at break to increase with $102.8 \%$ for PP and $58.9 \%$ for PA6, when compared to value obtained for $10 \mathrm{~mm} / \mathrm{min}$, but for the manufactured blends this increase is lower, the greater for material B (21\%) and the lowest for material C $(10.70 \%)$. The conclusion is that blend PP+PA6 decreases the stress at break, making it less sensible to test speed.

The values for stress at break (as average of five tests, figure 8) are in a narrow range for each material, except for PA6 at $10 \mathrm{~mm} / \mathrm{min}$. Materials A and B (with low content of polypropylene) have lower values and materials $\mathrm{C}$ and $\mathrm{D}$ (with high content of PA6) have higher values. Comparing A to D, this characteristic is higher for the latest with $26 \%$ at $\mathrm{v}=10 \mathrm{~mm} / \mathrm{min}, 41.9 \%$ at $\mathrm{v}=250 \mathrm{~mm} / \mathrm{min}, \mathrm{v}=500$ $\mathrm{mm} / \mathrm{min}$ and $34.1 \%$ for the highest testing speed ( $\mathrm{v}=1000 \mathrm{~mm} / \mathrm{min}$ ). But the differences between $\mathrm{C}$ and $\mathrm{D}$ for this characteristic are smaller. $\mathrm{D}$ has the same value $(37 \ldots 38 \mathrm{MPa})$ for all testing speeds, except for the smallest one.

G'sell, Bai and Hiver tested the following values of the ratio for PP/PA6/POE blends: 85/10/5, $70 / 20 / 10,55 / 30 / 15$ and 40/40/20 and noticed important dilatation, produced by plastic deformation under tension of neat PP and four PP/PA6/POE (polyethylene-octene elastomer) blends [21], [24]. At 
low a content of PA6, dilatation results from decohesion of the PA6 particles from the PP matrix. As the amount of PA6 and POE increases, voids are nucleated, preferentially in the thicker POE interphase, making a shell around the PA6 particles, and secondarily in isolated POE particles. The overall volume dilatation decreases with total alloying content and the authors supposed the implication of the following processes: the increasing contribution of PA6 that intrinsically deforms with less cavitation than PP, the post-cavitation rubber-like stretching of POE particles and the early formation of a percolating network of shear bands from the diffuse array of voids formed after the yield point. These mechanisms explain the gradual increase of the resistance to impact of the $\mathrm{PP} / \mathrm{PA} 6 / \mathrm{POE}$ as their alloying content is increased.

As Sover et al. [29] also reported for PP and PA66 (each with and without graphite), the elongation at break decreases when the test speed increases and that conclusion was obtained for all tested materials.

All blends have this characteristic lower than each component of the blend. At lower testing speeds, for PP, elongation at break decreases from 15.7 to $9.6 \%$, but for PA6, this decrease is larger (from $56 \%$ to $17 \%$ ). At higher testing speeds, for the same characteristic, the difference becomes smaller: PP has values from 9.9\% to $8.6 \%$ and PA6 has values from $15.2 \%$ to $10.8 \%$. The blends have this characteristic much lower and less dependent to the testing speed, but it is obviously that the high content of PP gives lower values for elongation at break.

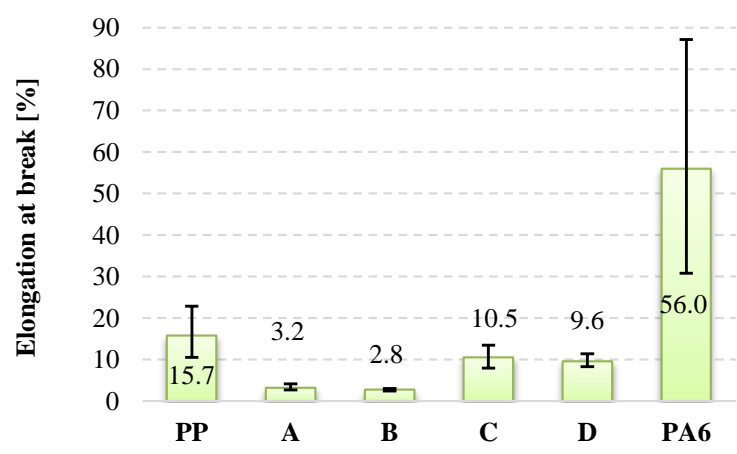

a) $10 \mathrm{~mm} / \mathrm{min}$

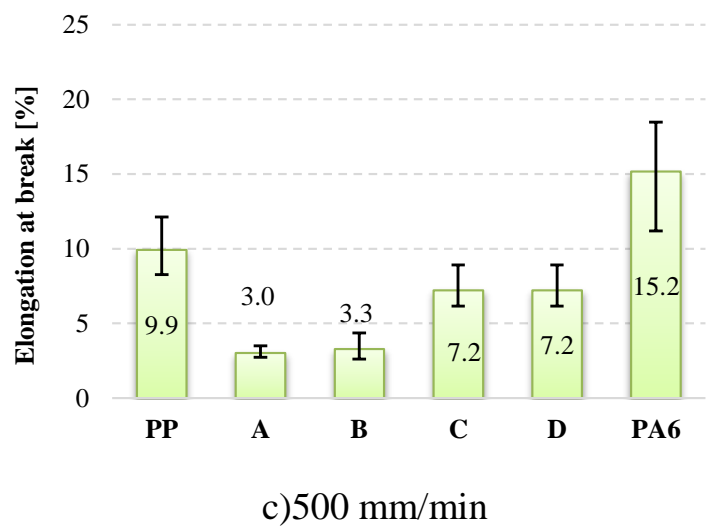

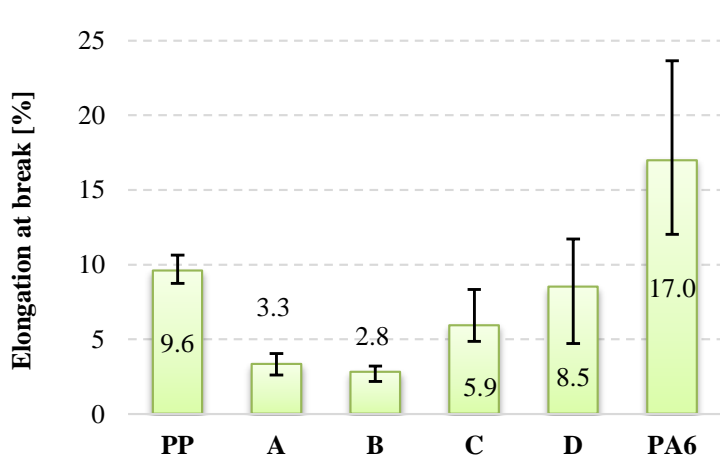

b) $250 \mathrm{~mm} / \mathrm{min}$

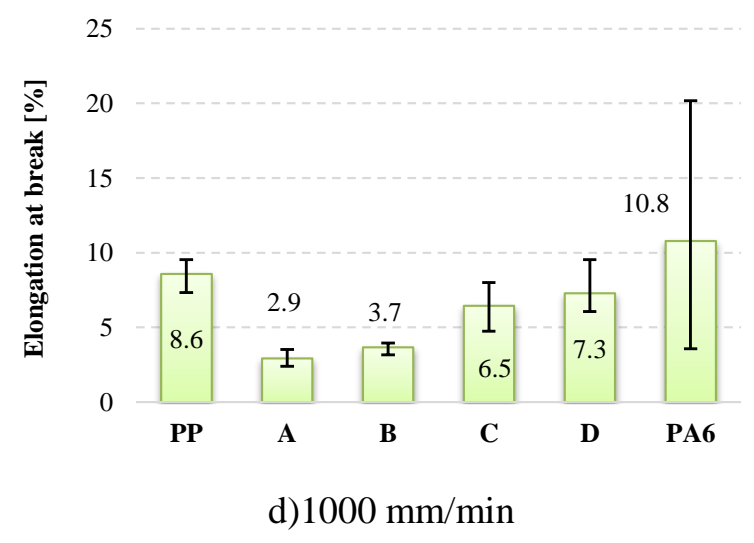

Figure 9. Elongation at break for all formulated blends at different deformation rate 


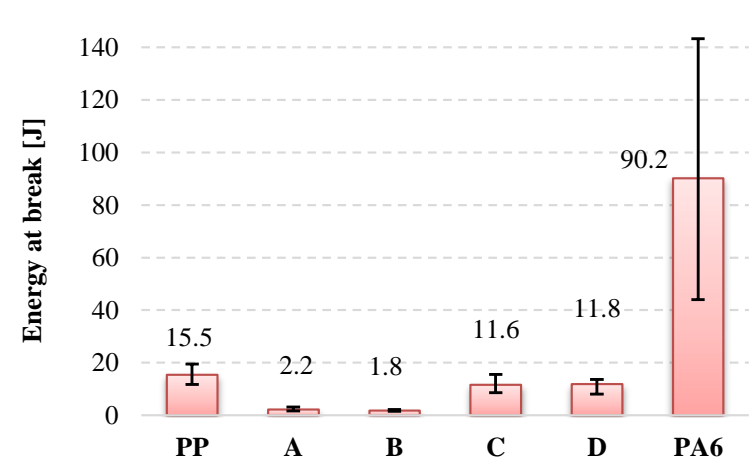

a) $10 \mathrm{~mm} / \mathrm{min}$

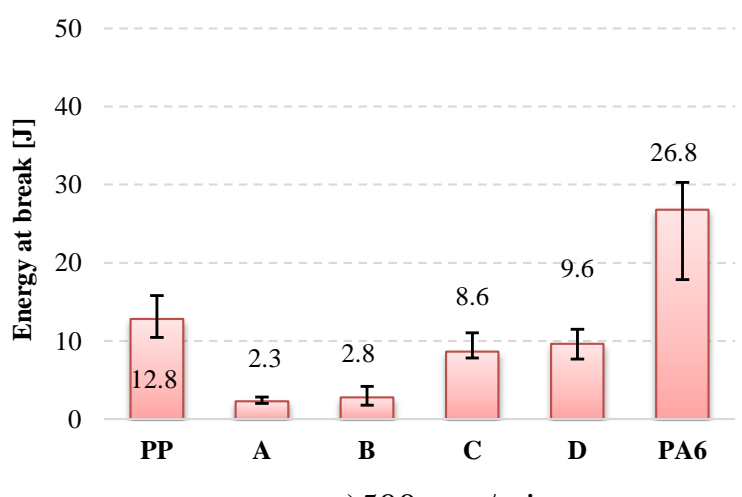

c) $500 \mathrm{~mm} / \mathrm{min}$

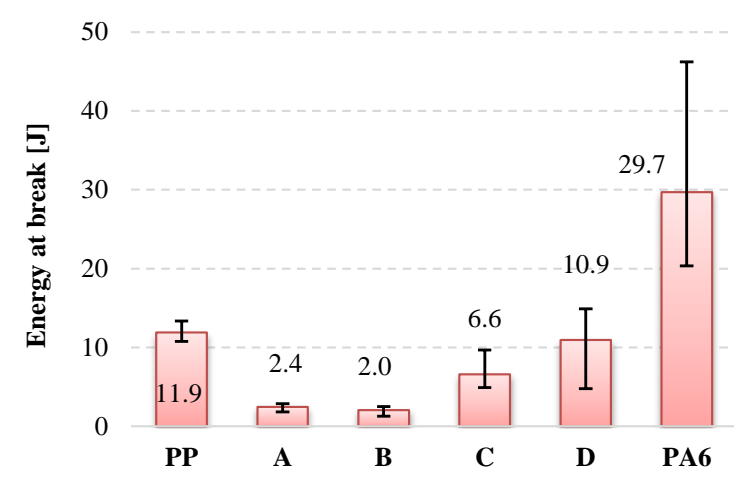

b) $250 \mathrm{~mm} / \mathrm{min}$

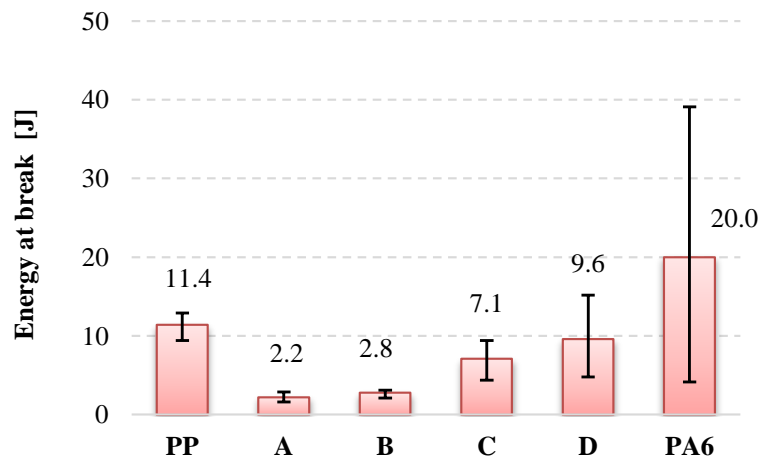

d) $1000 \mathrm{~mm} / \mathrm{min}$

Figure 10. Energy at break for all formulated blends at different testing speeds

A higher content of PA6, materials C and D, makes this characteristic higher.

Energy at break has similar evolution:

- the highest value, for each testing speed was obtained for PA6, followed by the value for PP,

- blends have much lower values,

- the blends could be grouped in two classes: with the lowest values for low concentration of PA6 and with higher values at high concentration of PA6.

PA6 has the highest values, but the spread interval is the largest, thus, adding PP in PA6 makes the formulated blends more predictible, at least for two characteristics: elongation at break and energy at break.

Figure 11 presents the influence of increasing PA6 concentration (and, consequently, decreasing PP concentration) on four mechanical characteristics. For PA6, in this figure, the value of elongation at break (55.98\%) and the energy at break $(90.15 \mathrm{~J})$ are not on the scale as the authors would like to point out in detail the influence of concentration in PA6 for the rest of materials.

Elongation at break also grouped the blends in two classes (figure 11b):

- materials A and B have low values (2.75\%...3.51\%), slightly decreasing with the testing speeds,

- materials $\mathrm{C}$ and $\mathrm{D}$ with higher values.

Energy at break (figure 11c) also makes distinctive the same groups of materials: A and B with lower values $\left(\begin{array}{llll}1.8 & \mathrm{~J} & 2.8 \mathrm{~J}\end{array}\right)$ and the group of materials $\mathrm{C}$ and $\mathrm{D}$ with higher values and a more pronounced dependence on testing speed: for $\mathrm{C}$ this characteristic is $11.6 \mathrm{~J}$ at $\mathrm{v}=10 \mathrm{~mm} / \mathrm{min}, 6.6 \mathrm{~J}$ at $\mathrm{v}=250 \mathrm{~mm} / \mathrm{min}, 8.6 \mathrm{~J}$ at $\mathrm{v}=500 \mathrm{~mm} / \mathrm{min}$ and $7.1 \mathrm{~J}$ at $\mathrm{v}=1000 \mathrm{~mm} / \mathrm{min}$. For material $\mathrm{D}$ the trend is similar but with higher values than $\mathrm{C}$. 
Except for tests at $10 \mathrm{~mm} / \mathrm{min}$, the Young modulus is in the range of $1800 \mathrm{MPa} . .1900 \mathrm{MPa}$, this range being only approx. $5 \%$ of the higher value, meaning that the test speed has not influence on this characteristic, at least for test speeds of $250 \mathrm{~mm} / \mathrm{min}$ to $1000 \mathrm{~mm} / \mathrm{min}$.

For PA6, at testing speeds of $250 \mathrm{~mm} / \mathrm{min}$ to $1000 \mathrm{~mm} / \mathrm{min}$, the Young modulus is insensitive to test speed (see also figure 7). Young modulus does not have a clear tendency of depending on PA6 concentration and testing speeds, but performs in a band between $1500 \ldots 1900 \mathrm{MPa}$, except for the value obtained for PA6 at the lowest testing speed ( $\mathrm{v}=10 \mathrm{~mm} / \mathrm{min}$ ), that is $1444 \mathrm{MPa}$. For PP and PA6, there were obtained the lowest values at testing speed $v=10 \mathrm{~mm} / \mathrm{min}$. For the blends, the dependence of Young modulus on the testing speed and PP/PA6 concentrations is weak.

Tensile stress at break

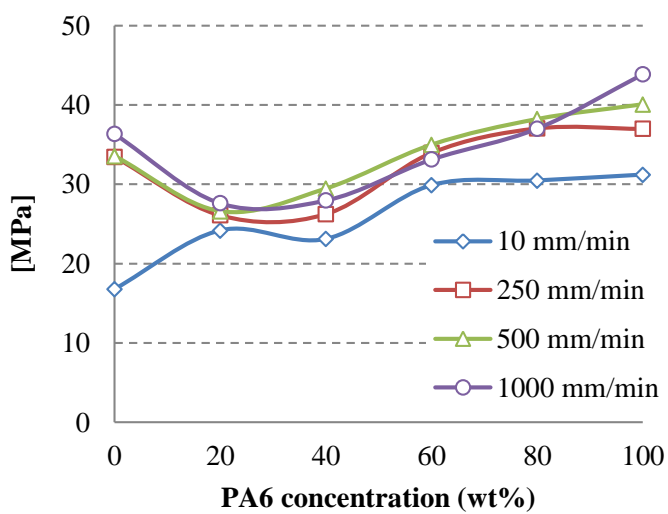

a

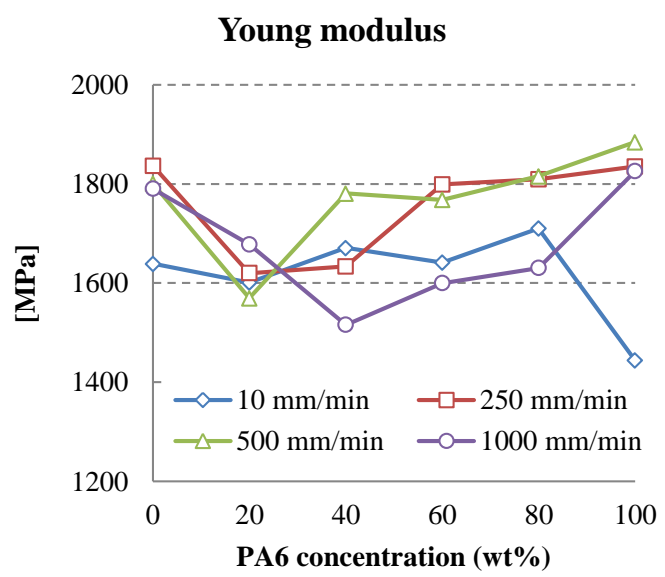

c
Elongation at break

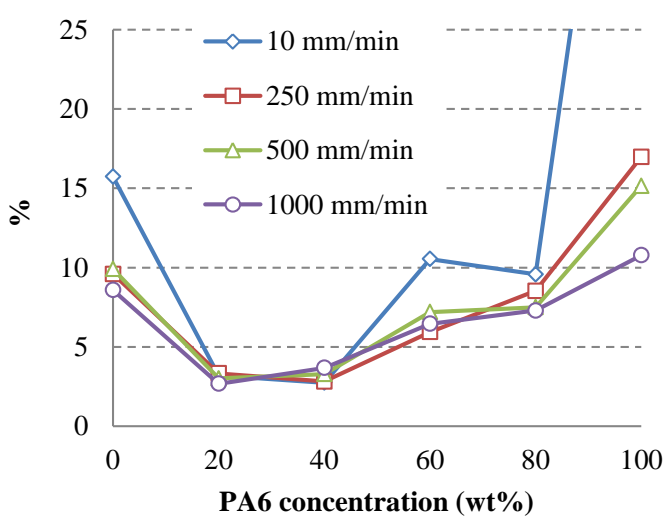

b

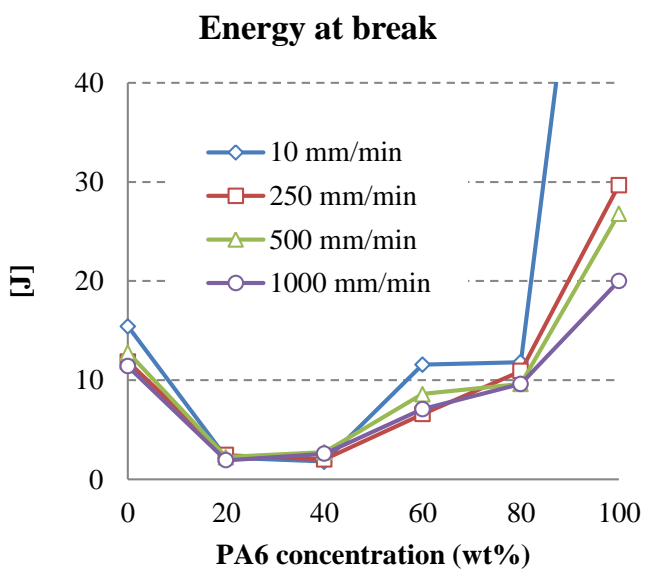

d

Figure 11. Mechanical characteristics as function of PA6 concentration and testing speed

Under higher testing speeds, the cracks are turned towards the loading direction, forming large parallel 'empty channels'. Investigations are needed on possible causes of these longitudinal voids in order to clear the cause of occurring during molding or loading and to eliminate them with the help of additives and by changing the molding and cooling regime (temperature and pressure).

Energy at break is very high $(90.15 \mathrm{~J})$ only for PA6 at the lowest test speed $(\mathrm{v}=10 \mathrm{~mm} / \mathrm{min})$. For $\mathrm{PP}$, this characteristic has a decrease of $26.45 \%$ when tested at $1000 \mathrm{~mm} / \mathrm{min}$, having as reference the value obtained at $\mathrm{v}=10 \mathrm{~mm} / \mathrm{min}(15.5 \mathrm{~J})$. Each of designed materials has the values for the energy at break concentrated in a range of several joules, in spite of different test speeds. There is an increase of this characteristic with the concentration of PA6 (figure 11d), especially for concentrations of $60 \%$ and $80 \%$ wt PA6. The value of energy at break for material D (PP $+80 \%$ PA6) is only $13.08 \%$ of the value characterizing PA6 at $\mathrm{v}=10 \mathrm{~mm} / \mathrm{min}$ and $48 \%$ of the same characteristic at $\mathrm{v}=1000 \mathrm{~mm} / \mathrm{min}$.

The lowest value for the tensile stress at break was obtained for PP at v=10 mm/min, 16.79 MPa. 
Except this, the average values for tensile stress at break perform in a band of $23 \mathrm{MPa}$, these being hard to be ranked based on testing speed (figure 11a). Except for PP at $\mathrm{v}=10 \mathrm{~mm} / \mathrm{min}$, the lowest values were obtained for materials $\mathrm{A}$ and $\mathrm{B}$. For C and D this characteristic slightly increased with the concentration in PA.

The elongation at break is less than $4 \%$ for materials with $20 \%$ and $40 \%$ PA6, between $6 \%$ and $10 \%$ for the materials with $60 \%$ and $80 \%$ PA6. The lowest values were obtained for A (with $20 \%$ PA6). For C and D, the difference between values, at the same testing speed, is the smallest. For PP, elongation at break varies with only $1.3 \%$ between values, at $250 \ldots 1000 \mathrm{~mm} / \mathrm{min}$. For the material A, the elongation at break diminishes with only $0.6 \%$ from tests done with $250 \mathrm{~mm} / \mathrm{min}$, to tests done with $1000 \mathrm{~mm} / \mathrm{min}$ and for material B this difference is $0.9 \%$, for material C $-1.3 \%$, for material D $2.0 \%$ and for PA6 $-6.2 \%$. This recommends the blends A and B for parts that require dimensional stability till fracture.

The fractured surfaces were observed with the help of a scanning electron microscope SEM, after being gold coated.

Figure 12 points out the central voids for material D, as obtained after molding and testing, very probable due to differentiate properties of the main component in the blend (PP and PA6).

When PP +PA6 blends are bearing a tensile load, a certain fraction of the overall strain is accommodated by conservative deformation of the material. In the PP matrix, deformation results from a combination of amorphous hyperelastic phase and crystal plasticity [23]. The PA6 phase is also capable to deform plastically, but its flow stress in the plastic stage is much higher than that of PP [24]. Consequently, in the PP/PA6 blends, the isolated PA6 particles exhibit less deformation than the PP matrix, leading to interfacial stress concentrations (figure 13, material A).

The isolated adhesive nodules try to keep the two polymer together, but not on the entire contact.

One type of damage mechanism is the interfacial debonding. Due to the contrast in the mechanical properties of adjacent materials, the induced stresses break the weak adhesion, leading to arc crack preferentially developing at the poles. Interfacial debonding is principally active for isolated PA6 particles.

As Bai et al. mentioned for similar blends [21], cavitation is one of energy dissipation processes during processing, actually controlling void nucleation and growth in these materials.

The morphology of PA/PP blend depends on the molecular weights of PA and PP and the degree of grafting. Typically, commercial polyamide/PP blends show PA as the continuous phase and PP as the dispersed phase. The morphology seems to be sensitive to induce shear effects and void generation during molding.

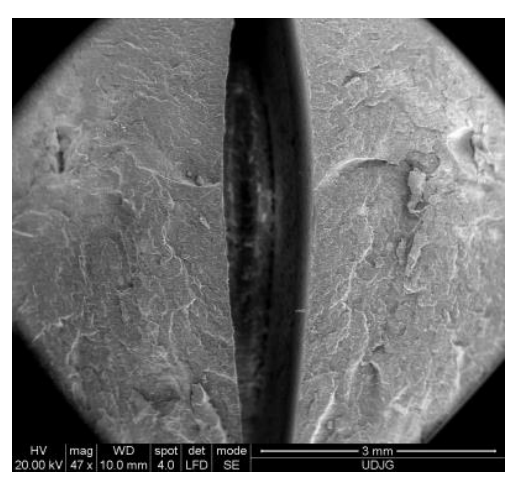

a) material $\mathrm{A}$

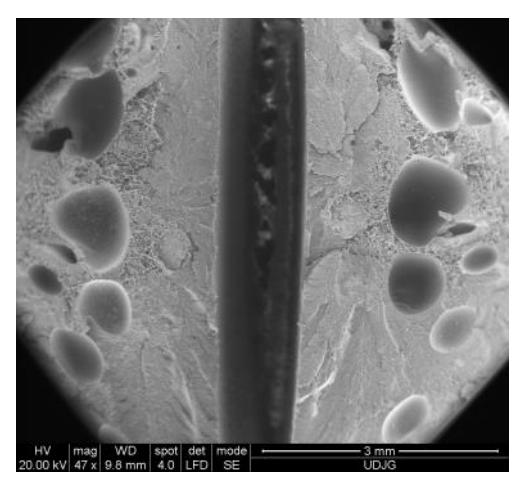

b) material D

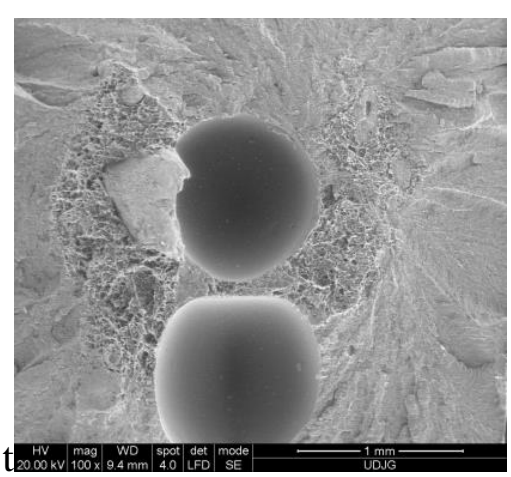

c) detail od material D

Figure 12. Fracture surfaces of the sample tested at $500 \mathrm{~mm} / \mathrm{min}$ 
$10 \mathrm{~mm} / \mathrm{min}$
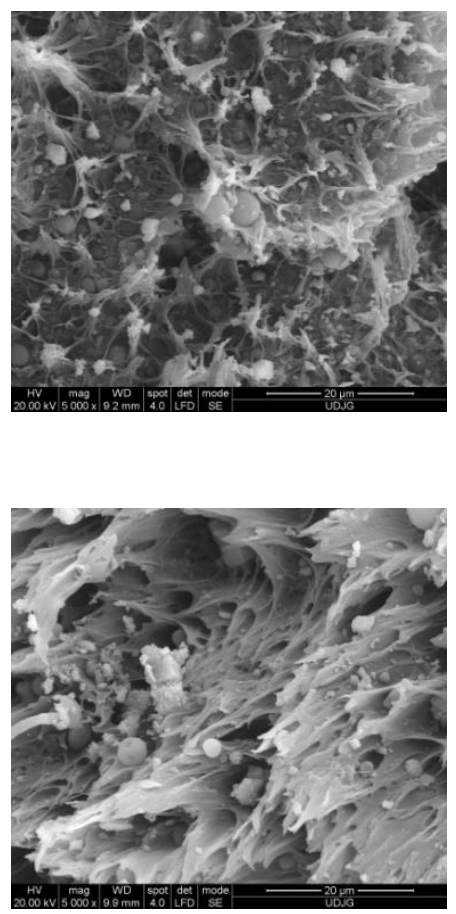

$250 \mathrm{~mm} / \mathrm{min}$

Material A
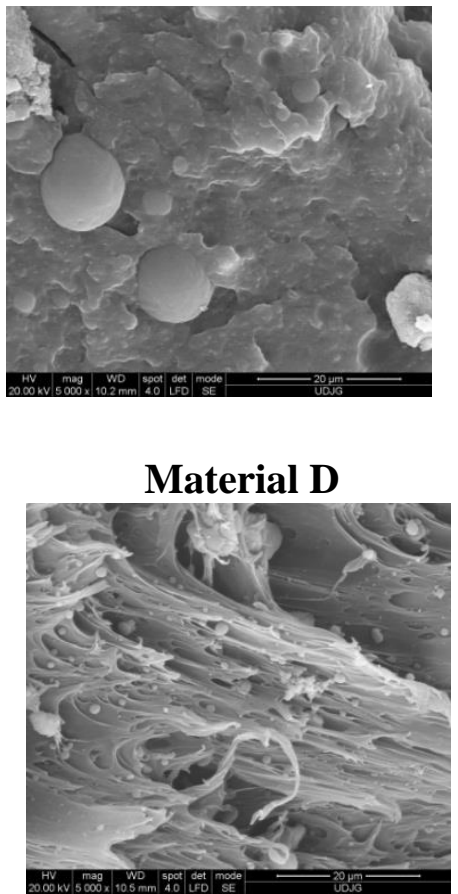

$1000 \mathrm{~mm} / \mathrm{min}$
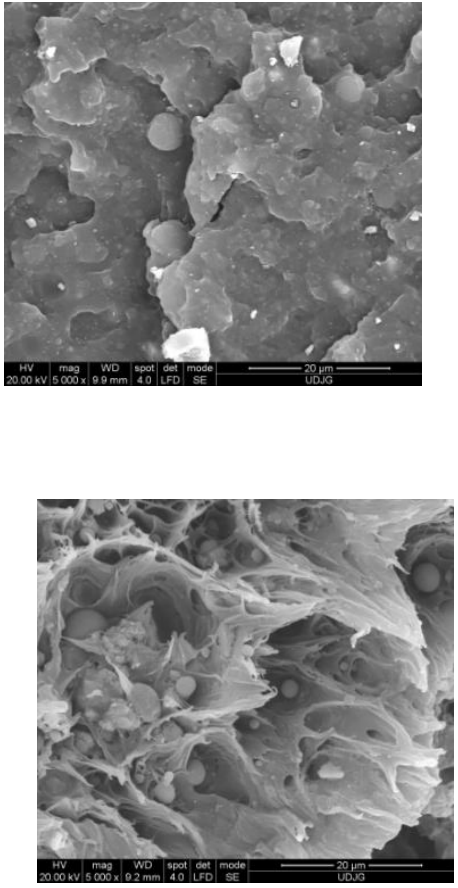

Figure 13. SEM images of the fractured surfaces

Comparing SEM images for the same material, one may notice that, for material A, the lowest testing speed allow for small volume of PA6 to be drawn. $\mathrm{CaO}_{3}$ particles are visible as small white spots, uniformly distributed. At higher testing speed, the small nodules of PA6 are keeping their almost spherical appearance, meaning the detaching process is occurring at their interfaces. The rupture surface has a more rough aspect for the PP matrix, for the highest testing speed as compared to that obtained at $\mathrm{v}=250 \mathrm{~mm} / \mathrm{min}$.

For material D, the island morphology is finer for this blend with $80 \%$ wt PA6, the ductile character of this component is obvious, but drawn bands of PA6 component are longer for $\mathrm{v}=10$ $\mathrm{mm} / \mathrm{min}$ (figure 13).

\section{Conclusions}

Taking into account the four formulated blends, material D (with 80\% PA6) is the most promising as has the highest stress and energy at break $(11.43 \mathrm{~J}$ at $\mathrm{v}=10 \mathrm{~mm} / \mathrm{min}$ and $8.7 \mathrm{~J}$ at $\mathrm{v}=1000 \mathrm{~mm} / \mathrm{min})$, but values are still less than PA6.

Increasing the PA6 content and, consequently, lowering the PP content of the blend, is favorable for mechanical characteristics, as following:

- energy at break is lower as compared to the polymer component increased, but by passing from A to $\mathrm{D}$, this characteristic increases; $\mathrm{A}$ and $\mathrm{B}$ have close values very less dependent on testing speed; values for $\mathrm{C}$ are more spread, but for $\mathrm{D}$ are the highest among blend values;

- except for PA6 tested at $10 \mathrm{~mm} / \mathrm{min}$, the elastic modulus has values in a band of approximately $350 \mathrm{MPa} ; 20 \%$ PA6 decreases all values for Young modulus but keeping a clear dependence on testing speed;

- tensile at break should be discussed for $\mathrm{v}=10 \mathrm{~mm} / \mathrm{min}$ and for the other three testing speed: material A has all these values grouped in an interval of $3 \mathrm{MPa}$ and $\mathrm{B}$ in a larger one of $6 \mathrm{MPa}$. The curve for $\mathrm{v}=10 \mathrm{~mm} / \mathrm{min}$ is the lowest, $\mathrm{A}$ and $\mathrm{B}$ having close values as $\mathrm{C}$ and $\mathrm{D}$, but lower; for the other three speeds, the stress at break increases with PA6 concentration, in range of $4 \ldots 6 \mathrm{MPa}$, but not clearly influenced by speed, 
- the elongation at break remains at low values and less influenced by the test deformation rate as compared to PA6.

Adding PP in PA6 makes the formulated blends more predictible, at least for two characteristics: elongation at break and energy at break.

The technology has to be improved for eliminating the voids in the blends with high PA6 concentration and the research study has to be done again.

Acknowledgment. This work has been supported by the European Social Fund through the Sectorial Operational Programme Human Capital 2014-2020, "Scholarships for entrepreneurial education among doctoral students and postdoctoral researchers (Be Antreprenor!)", Contract no. 51680/09.07.2019 - SMIS code: 124539.

\section{References}

1.UTRACKI, L.A., Polymer Blends Handbook, Kluwer Academic Publishers, Dordrecht, 2002.

2.SHARMA, K.R., Polymer Thermodynamics. Blends, Copolymers and Reversible Polymerization, CRC Press Taylor \& Francis Group, 2012.

3.ROBESON, L.M., Polymer Blends: A Comprehensive Review (Hanser. Gardner, Munich), 2007.

4.CIRCIUMARU, A., Caracterizarea şi Testarea Materialelor Polimerice, Europlus, Galati, 2013.

5.BOTAN, M., GEORGESCU, C., PIRVU, C., DELEANU, L., 22nd Intern. conf. on materials and technology, Portoroz Slovenia, 53, 2014.

6.SUI, G., JING, M., ZHAO, J., WANG, K., ZHANG, Q., FU, Q., Polymer, 154, 2018, p. 119.

7.SHI, S., HUANG, P., NIE, M., WANG, Q., Polymer, 132, 2017, p. 23.

8.PANAITESCU, D.M., IORGA, M.D., SERBAN, S., FRONE, A.N., Mater. Plast., 47, (1), $2010,1$.

9SHEN, C., ZOU, Y., DOU, R., WANG, W., YIN, B., YANG, M., Polymer, 56, 2015, p. 395.

10.PALACIOS, J.K., SANGRONIZ, A., EGUIAZABAL J.I., ETXEBERRIA A., MULLER A.J., European Polymer Journal, 85, 2016, p. 532.

11.LAOUTID F., ESTRADA E., MICHELL R.M., BONNAUD L., MULLER A.J., DUBOIS P., Polymer, 54, 2013, p. 3982.

12.WANG, L, SHI, C., GUO, X.Z., YU, J, 2014, Journal of Industrial and Engineering Chemistry, 20, p. 259.

13.IDE, F., HASEGAWA, A., J APPL POLYM SCI, 18, no.4, 1974, p. 963.

1.AKKAPEDDI, K., Commercial Polymer Blends, in Polymer blends handbook, ed. Utracki, L.A., vol. 1, Kluwer Academic Publishers, 2002, p. 1063.

15.SANGRONIZ, L., PALACIOS, J.K., FERNANDEZ, M., EGUIAZABAL, J.I., SANTAMARIA A., MÜLLER A.J., European Polymer Journal, 83, 2016, p. 10.

16.ALEXANDRESCU, L., SONMEZA, M., GEORGESCU, M., NITUICA, A., FICAI, R., TRUSCA, R., GURAU, D., TUDOROI, L., Procedia Structural Integrity, 5, 2017, p. 675.

17.BEUGUEL, Q., VILlE, J., CREPIN-LEBlOND, J., MEDERIC, P., AUBRY, T., APPL CLAY SCI, 147, 2017, p. 168.

18.KODAL, M., Polymer, 105, 2016, p. 43

19.MOTAMEDI, P., BAGHERI, R., Composites Part B, 85, 2016, p. 207.

20.CHEN, J.K., HUANG, Z.P., MAI, Y.W., Acta Mater, 51, 2003, p. 3375.

21.BAI S., G’SELL C., HIVERC J.M., MATHIEU C., Polymer, 46, 2005, p. 6437.

22.IPPOLITO, F., RENTSCHA, S., HUBNERB, G., CLAYPOLEC, T., GANE, P., Composites Part B, 164, 2019, p. 158.

23.G'SELL, C., DAHOUN, A., FAVIER, V., HIVER, J.M., PHILIPPE, M.J., CANOVA, G.R., Polym Eng Sci 1997, 37, p. 1702.

24.G'SELL, C., BAI, S.L., HIVER, J.M., Polymer, 45, 2004, p. 5785.

25.*** Omyacarb 2VA, http://www.kcdoupe.cz/media/files/materials/10_12_OMYACARB.PDF

26.*** POLYBOND® 3200, https://www.addivant.com/content/polybond\%C2\%AE-3200-polymer- 
modifier

27.*** SR EN ISO 527-2:2012 Plastics. Determination of tensile properties. Part 2: Test conditions for moulding and extrusion plastics

28.MINDRU, T.D., CIOFU, D.C., Mater. Plast., 49, (4) 2012, p. 279.

29.SOVER, A., MARZYNKEVITSCH, S., MUNACK, B., Mater. Plast., 55, (4), 2018, 507.

$\overline{\text { Manuscript received: } 19.01 .2020}$ 